\title{
Escena del crimen: Viena Una guía turístico-criminal desde el fin de siglo hasta nuestros días (II)
}

\author{
Martin SCHATZMANN WILLVONSEDER \\ mschatzmann@yahoo.com
}

Recibido: 30 de octubre de 2010

Aceptado: 15 de noviembre de 2010

\section{Resumen}

Viena muestra una imagen nítida como capital turística, con el peso histórico de una metrópoli imperial. Este artículo quiere contrastar la realidad de esta arquitectura tópica con otra imagen de la ciudad actual, una imagen menos turística, menos conocida y probablemente menos atractiva, sin embargo también real. Además analiza la transformación de la función de lugares públicos y fronterizos. Para este fin, comparo la perspectiva externa de la ciudad con la interna, y la visión femenina con la masculina, en base a una serie de novelas policíacas que desarrollan su trama en Viena.

Palabras clave: Viena, novela policiaca, monumentos, parques, locales, hospitales, símbolos, II Guerra Mundial, historia, Austria.

Title: Crime scene: Vienna. A criminal tourist guide from the fin de siècle to our days (II)

\section{Abstract}

Vienna has a clear reputation as a capital of tourism with the historic weight of an imperial metropolis. This article proposes to contrast the reality of this architectural cliché with other contemporary images of the city, less touristic, less known and probably less attractive, yet equally real. It also analyzes the transformation of the purpose in public and border places. Therefore I compare the perspective from outside with the one from inside and the feminine point of view with the masculine, based on a series of detective novels that develop their plot in Vienna.

Keywords: Vienna, detective novels, monuments, parks, pubs, cafés, hospitals, symbols, IIWW, history, Austria.

\section{Barrios ricos, barrios pobres}

La Viena de contrastes, con su distinción entre barrios con habitantes de distintos estratos, tiene mucha importancia para todos los autores. Para describir la situación social de hace un siglo es Frank Tallis quien pinta estas diferencias con más intensidad, marcando tanto lo espléndido como lo sórdido de la arquitectura y los personajes. El centro de la ciudad y especialmente el lujo burgués de la Ringstrasse brillan con luz propia. El polo opuesto, con el lugar del crimen, lo encuentra Tallis en el barrio de Leopldstadt: "Las avenidas principales de Leopolstadt [sic] eran respetables, pero los barrios apartados 
seguían siendo destartalados y venidos a menos. Los altos edificios, viejos y deprimentes, bloqueaban casi el cielo" (Tallis 2009: 74) ${ }^{11}$.

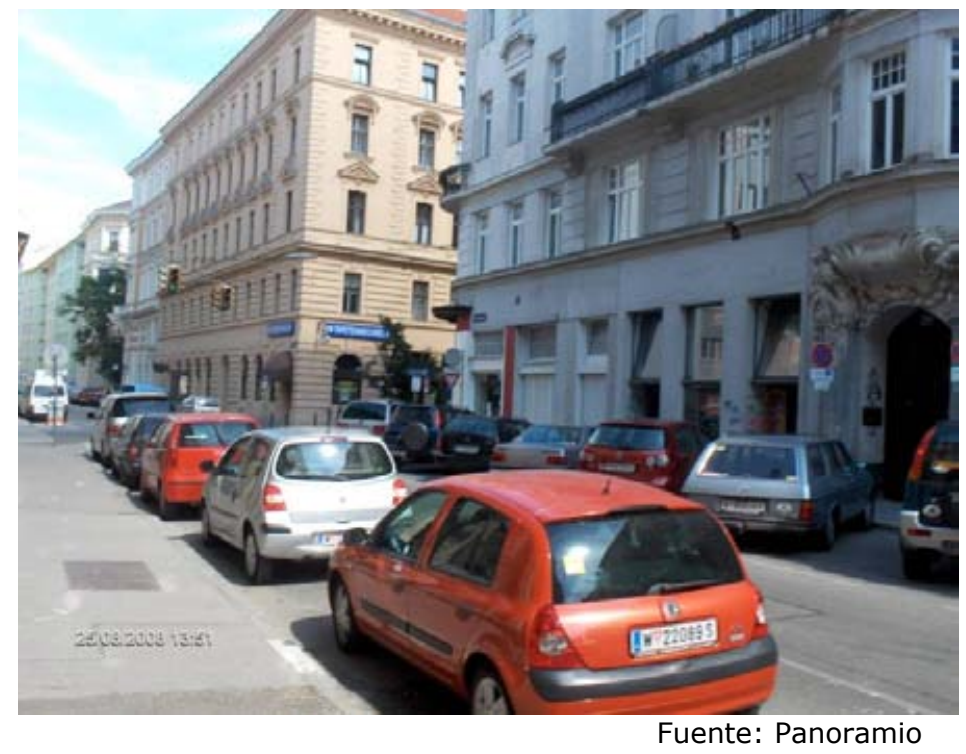

Figura 32. Leopoldstadt Zirkusgasse

Lo que hoy es un barrio bastante céntrico todavía conserva cierto aire provinciano, con su plaza de mercado y sus tiendas baratas (Tallis 2006: 255). Además, detrás de esta fachada, empieza un laberinto de calles pobres con cafés turcos y prostitutas esperando bajo las farolas de luz de gas. El recuerdo del esplendor pasado deja un sabor melancólico:

Alguna vez había debido de ser bonita. En algunos huecos se veían todavía los restos de varias estatuas y se adivinaba también un fantasmal trabajo de relieve dorado, formado por gruesos trenzados y ramajes espectrales. La puerta principal era maciza y estaba decorada con una reja de hierro oxidado que sugería el rastrillo de un castillo medieval. (Tallis 2009: 104)

Las mesas de los puestos del mercado habían quedado en el exterior, y la ligera brisa agitaba retazos de las lonas y toldos sueltos. Los edificios de alrededor del mercado eran relativamente grandes, algunos de hasta seis pisos de altura, y estaban pintados con brillantes colores: naranja, amarillo, verde lima y rosa. Sin embargo, la impresión de conjunto no era de alegría sino de deterioro, pues los edificios habían perdido su lustre festivo bajo una capa de mugre. (Tallis 2009: 286-287)

${ }^{11}$ El autor nos permite situar el lugar del crimen con los nombres de las calles, curiosamente ubicando la comisaría exactamente donde se encuentra hoy día el Museo de Criminología. 
Es como si el centro elegante de Viena estuviera sitiado por barrios pobres. Los barrios burgueses conquistaron a mitad del siglo XIX las anacrónicas defensas y el glacis de la capital, que ya se habían mostrado inútiles ante Napoleón (Kleindel 1984: 287). En la Viena fin de siglo, la nueva amenaza llegaba desde el interior de una sociedad multinacional, un peligro que no se puede controlar con murallas.

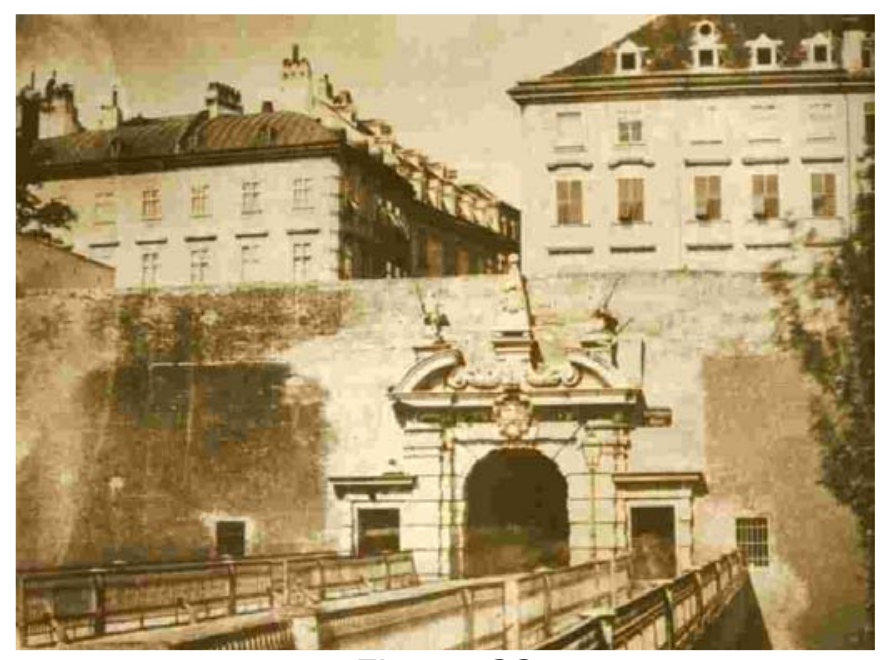

Figura 33

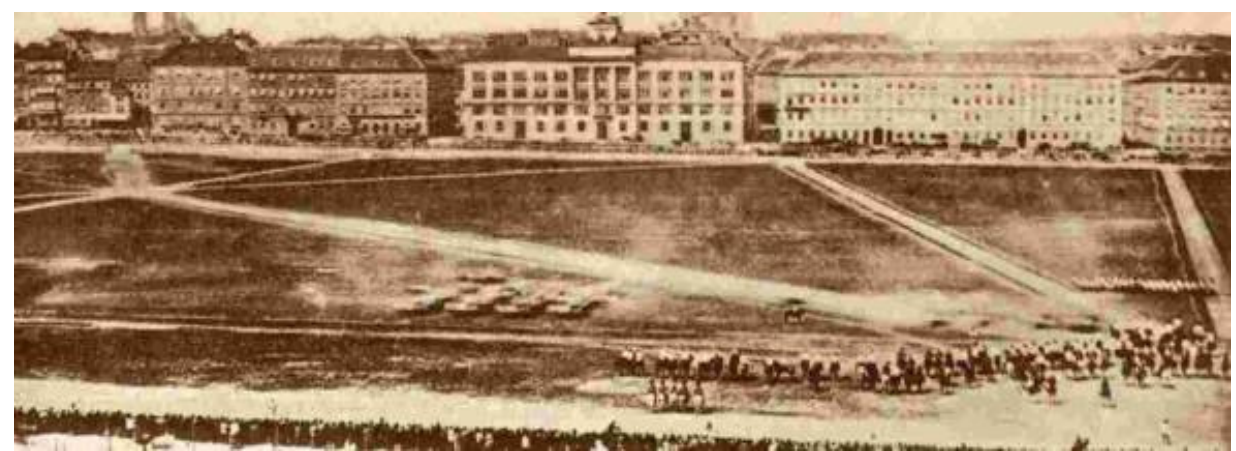

Figura 34 
SCHATZMANN WILLVONSEDER, Martin (2011): "Escena del crimen: Viena. Una guía turístico-criminal desde el fin de siglo hasta nuestros días (II)" [en línea]. En: Ángulo Recto. Revista de estudios sobre la ciudad como espacio plural, vol. 3, núm. 1, pp. 5-30. En: http://www.ucm.es/info/angulo/volumen/Volumen03 -1/articulos01.htm. ISSN: 1989-4015

http://dx.doi.org/10.5209/rev_ANRE.2011.v3.n1.1950]

Viena es claramente una ciudad circular marcada por la avenida de la Ringstrasse, que se extiende por el "cinturón", el Gürtel ${ }^{12}$.

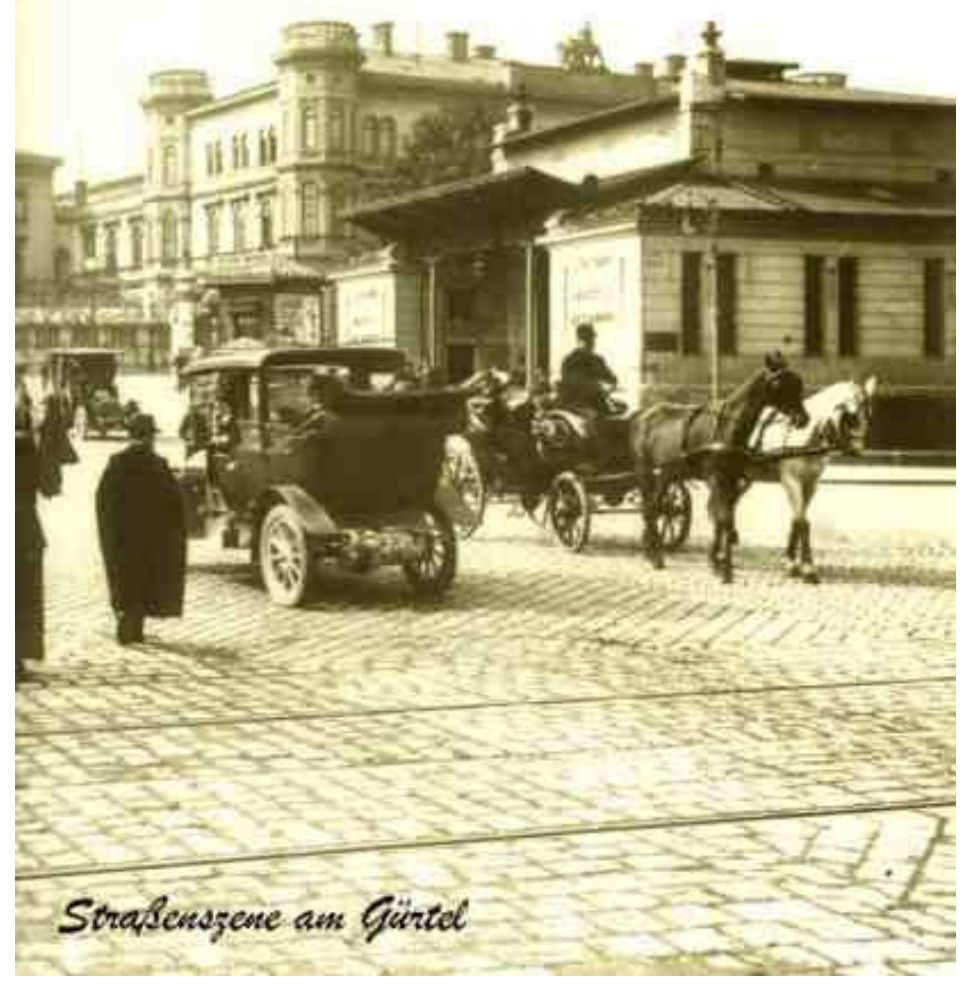

Figura 35

12 La reputación del Gürtel como arteria principal del tráfico queda documentada en los libros de los autores austriacos. Lo que permite a la gente moverse, no les deja vivir: "Un callejón estrecho y sombrío incluso durante una mañana clara, justo antes del cinturón de Viena. La polución, el ruido, el polvo y la suciedad de esta arteria principal del tráfico se percibían con toda claridad. [...] Este edificio, como otros en sus alrededores, había sido construido después de la guerra" (Rossmann 2008a: 190). Si Rossmann destaca el incremento de la polución que disminuye la calidad de vida en la zona, Wolf Haas critica a su manera el peligro para la vida misma, cuando se abusa del Gürtel como autopista urbana. "Dos kamikazes de carreras de dieciocho años, con las matrículas personalizadas Pole $I$ y Elvis I, habían montado un duelo en pleno tráfico laboral del cinturón entre la estación del oeste y la Schlachthausgasse. Pero el Audi Quattro negro no había llegado hasta la Schlachthausgasse, y tampoco el Alfa rojo. Porque primero resbaló el Audi Quattro con la matrícula Elvis $I$ en el cinturón de Gaudenzdorf y luego el Alfa rojo se incrustó a toda velocidad en el Quattro. iPero así son las cosas! Mientras que Brenner estaba limpiando el cerebro de los dos jovencitos de la barrera central, algo se movió de repente en su propio cerebro" (Haas 1998: 163). 


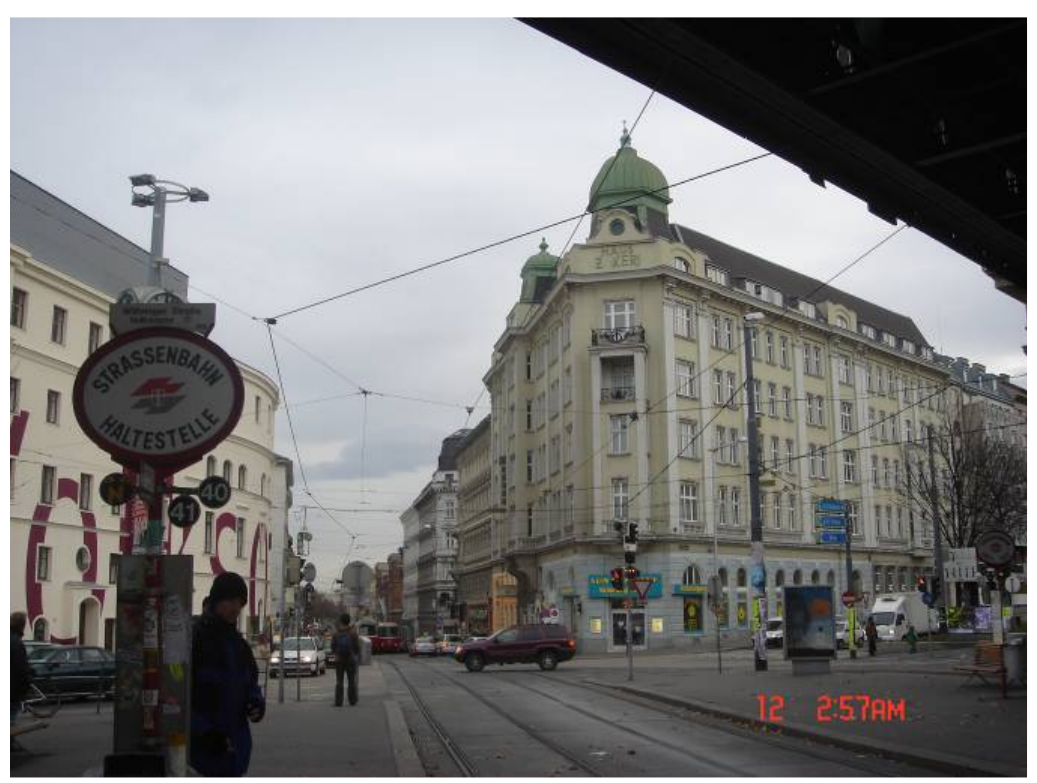

Figura 36

Como tal, tiene a principios del siglo XX un centro imperial, alrededor un Ring burgués y un extrarradio obrero, separación que se irá difuminando a través del tiempo. Además podemos observar una separación entre este y oeste, con el Danubio como referencia hacia el norte. El palacio y los jardines de Schönbrunn al suroeste fomentaron la construcción de una réplica burguesa, el barrio residencial de Hietzing. Al norte sobresalen los distritos Alsergrund (Tallis 2006: 324), Heiligenstadt (Tallis 2006: 210) y Döbling (Rafelsberger 2009: 9) con casas señoriales.

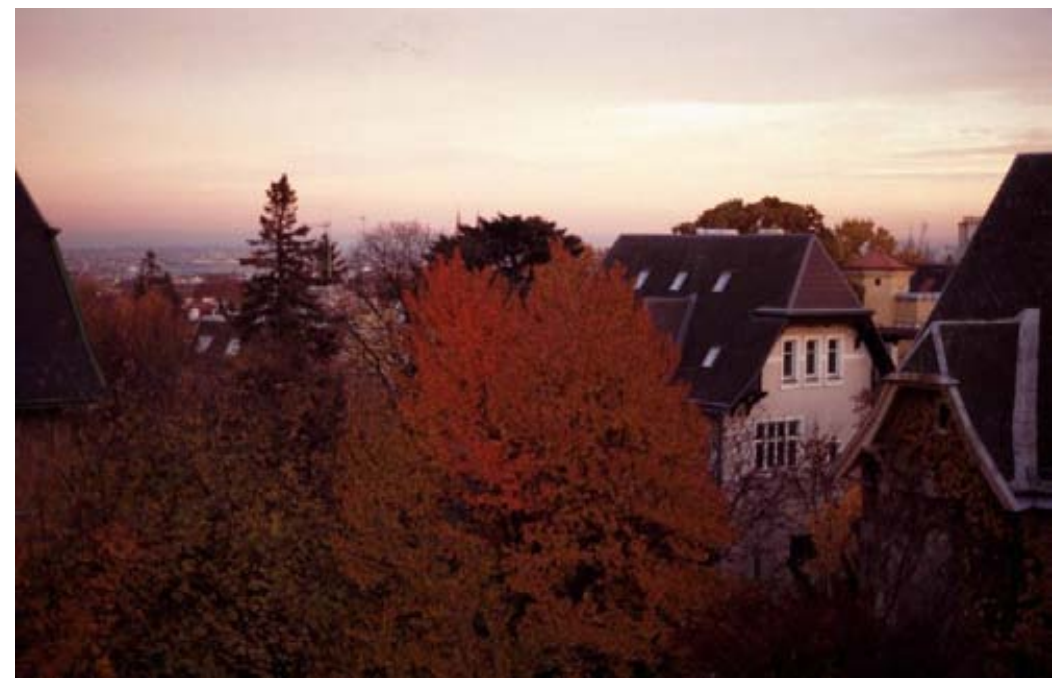

Fuente: Panoramio

Figura 37. El distrito de Döbling 
A estos barrios se opone, en opinión de Tallis, el barrio obrero Meidling al sureste, donde precisamente se encuentran dos sospechosos, el colaborador y un cliente extravagante de la difunta pitonisa, en un burdel barato.

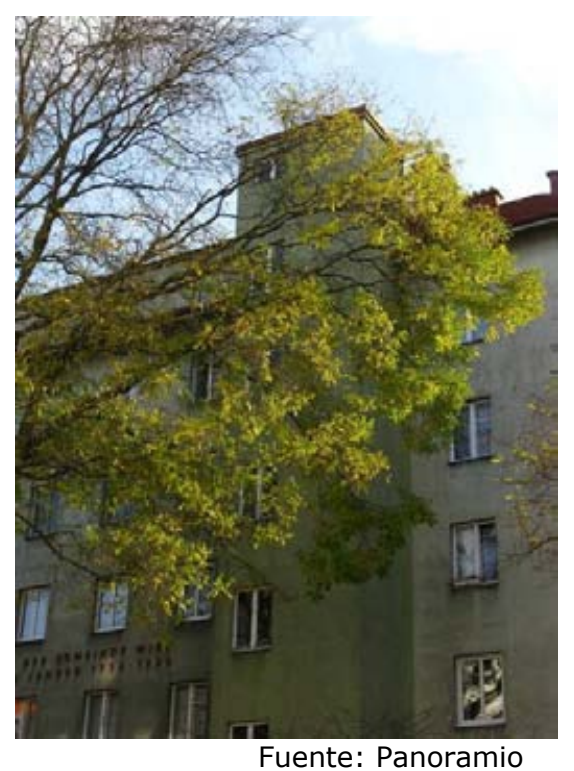

Figura 38. Meidling

Nombres eslavos sugieren una repartición étnica de la capital multirracial (Tallis 2006: 237). No parece casualidad que se mencione -aunque sea sólo brevemente- la ciudad de los muertos, el cementerio del Zentralfriedhof, también al Este de Viena.

Leopoldstadt, el barrio judío, en el noreste, es más difícil de definir. No es solamente un barrio donde se forjan carreras turbias de fraude y crimen, donde las señoras no se atreven a pasear a solas. A pesar de su nombre imperial, estaba situado al principio del siglo XX en las afueras, flanqueado por los parques Augarten y Prater. Enmarcado por el canal y el río Danubio era y es virtualmente una isla. Sus puertos fluviales y la Estación del Norte convirtieron Leopoldstadt en un portal de la capital para el comercio y la inmigración. Por razones históricas se trata de un barrio con una importante población judía. 


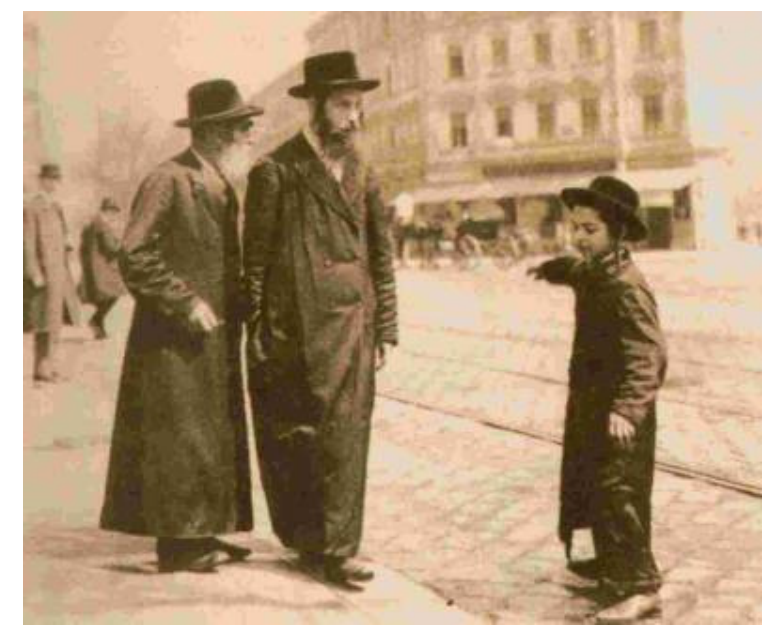

Figura 39

En resumen, es un barrio donde hombres ambiciosos llegaron a hacer carrera para poder entrar en la Viena imperial e instalarse en la Viena burguesa. Eso es lo que consigue la familia Liebermann en el libro de Frank Tallis. A través de la historia del barrio se conectan la vida del sofisticado protagonista con las vidas de los criminales que ayuda a investigar, única manera comprensible de volver a los suburbios y su mundillo de engaños. ¿Para qué volver pudiendo moverse en el centro, donde se toman las decisiones serias?:

Encontré bastante extraño que un hombre que se mezclaba con el alcalde y sus amigos, es decir, hombres preocupados por el acontecer y los problemas del mundo real, asistiera también a las sesiones de espiritismo de Leopoldstadt. (Tallis 2009: 188)

Esta caracterización social de los barrios también tiene su importancia para los autores austriacos. La protagonista de Eva Rossmann investiga en la Viena actual el distrito 21, más allá del Danubio. Este tiene aspectos comparables con el barrio Leopoldstadt de Tallis, al tratarse hoy día de la nueva periferia. Se caracteriza además por los no-lugares modernos, donde se instalan los que no han sabido encaminar su carrera:

La consejería estaba situada en un edificio feo y bajo, junto a un supermercado y una joyería baratos y algunas direcciones que inspiraban poca confianza, accesibles a través de una escalera al primer piso. Aquí Viena no era diferente a cualquier metrópolis del mundo. En la periferia había sitio para aquellos que no habían podido mantener el paso en la persecución de éxito y bienestar. (Rossmann 2008a: 82)

El "más allá del Danubio" como suburbio también encuentra su mención en Komm, Süßer Tod. Son barrios que dan a Viena las dimensiones de una urbe, pero le restan identidad: 
Puede que la muerte sea grande. Pero Viena también es grande. Cuando coges el cinco de la Estación del Oeste a la Estación del Norte tardas casi una hora. Y todavía no has llegado fuera, al Bronx. Falta mucho para las urbanizaciones Großfeld o Trabrenn o las afueras, como Schöpfwerk, donde los violadores y las bandas juveniles y los vendedores de periódicos. (Haas 1998: 165-166)

Los barrios satélite también se diferencian socialmente como apunta Wolf Haas con ironía. Así se acercan el Hietzing (Tallis 2006: 57) fin de siglo al Alt Erlaa, tanto geográfica como socialmente, y el Meidling fin de siglo al Schöpfwerk de hoy:

Yo digo: la muerte es grande y Viena también es grande. Y es verdad. Pero iel mundo es pequeño! Porque el señor Oswald vivía en Alt Erlaa y Lungauer también vivía en Alt Erlaa. Esa también es una de estas urbanizaciones satélite, pero no como Schöpfwerk ni como Großfeld, sino al contrario: Satélite de élite. Satélite de clase media. Ocho torres rascacielos y tantos habitantes como toda Eisenstadt. Con piscinas en los tejados y parques infantiles y todo. (Haas 1998: 166)

Mientras que los satélites pequeño-burgueses despiertan el sarcasmo de Haas, los barrios más elegantes como Hietzing y Döbling sólo aparecen puntualmente. Sus habitantes -con excepcionessuelen ser ricos y tacaños, ambiciosos y antipáticos. Aunque los poderosos suelen tener motivos para matar, en las novelas de Haas no se vinculan con estos barrios residenciales. En eso se distingue de la trama de Eva Rossmann, que localiza el origen del crimen en Freudsche Verbrechen, precisamente en una gran casa burguesa de un barrio noble. También Rafelsberger ubica a los criminales de su novela en este ambiente, donde se perpetran los crímenes más espantosos en los sótanos de magníficas villas (Rafelsberger 2009: 254). Este contraste de un entorno noble y elegante con la pérdida o perversión de los valores de sus habitantes parece precisamente parte del juego. 

ciudad como espacio plural, vol. 3, núm. 1, pp. 5-30. En: http://www.ucm.es/info/angulo/volumen/Volumen03 -1/articulos01.htm. ISSN: 1989-4015

\section{Los locales: cafés y Heurigen}

El punto común en los cuatro autores seleccionados y los barrios por ellos elegidos como marco de sus novelas son los locales típicos de Viena, entre los que destacan sobre todo los cafés y los Heurigen. Siendo Viena hoy la única capital europea con viñedos (Rafelsberger 2009: 28), los barrios al norte de Viena, como Döbling, donde abundan los Heurigen, eran hace cien años todavía pueblos (Tallis 2006: 172-173). De ahí proceden estas tabernas de vino local de la temporada, convertidas en toda una especialidad de la región.

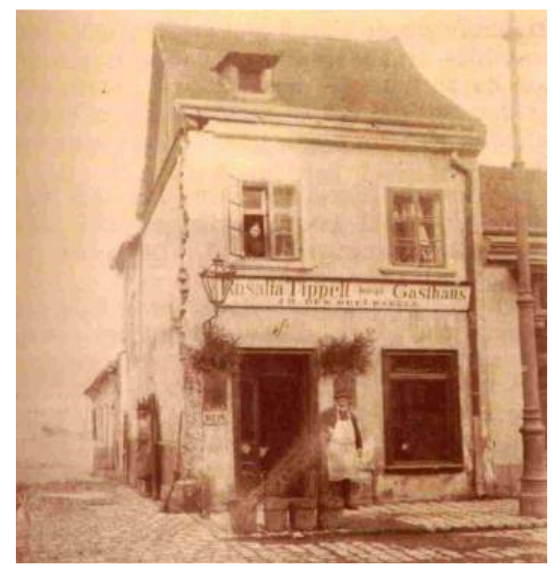

Figura 40

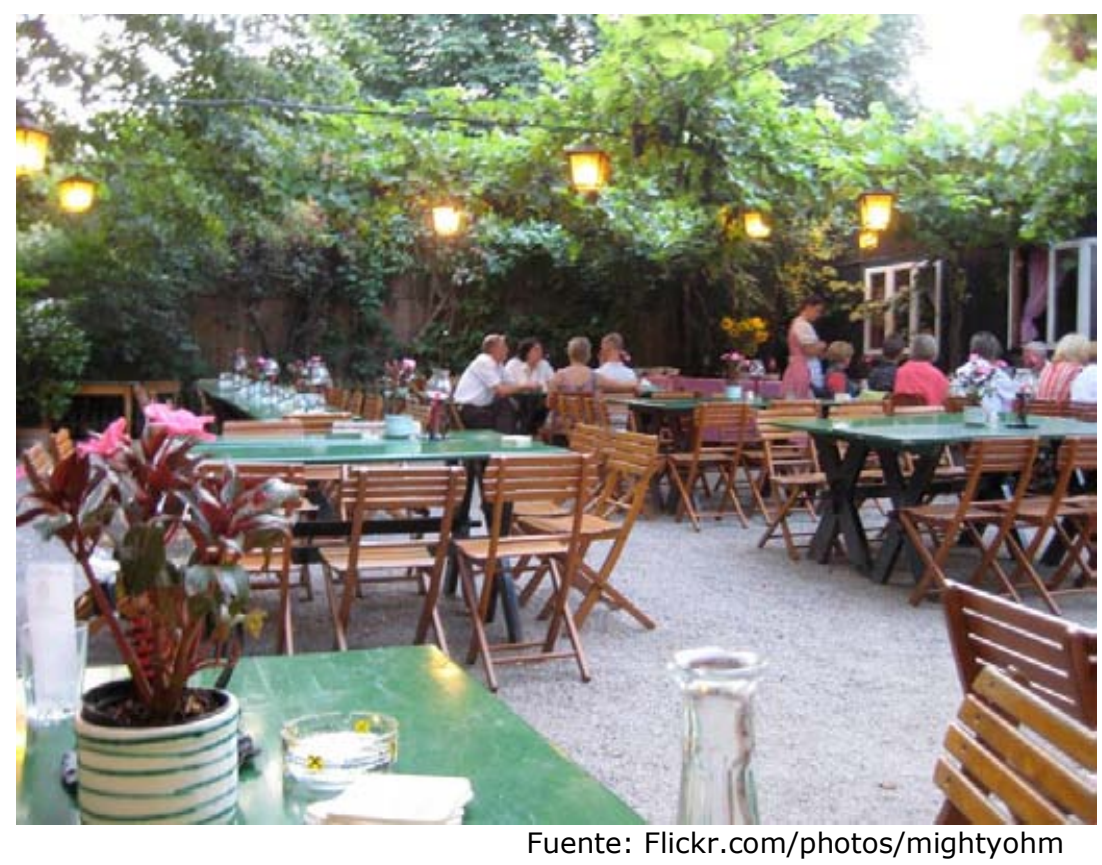

Figura 41. Heuriger 
Eva Rossmann, por su parte, dedica a la cocina un lugar importante en su historia, indagando en sus características y calidades $^{13}$. La profesión de la protagonista es lo que la lleva a fiestas celebradas en lugares turísticos que han perdido todo su carácter original. Rossmann resume bien su ambiente y lo contrasta luego con un Heuriger original, donde Mira Valensky encontrará esta mezcla de vino joven y una pequeña selección de especialidades caseras en un lugar humilde de pueblo. Este contraste hace pensar que es la ciudad y el propio éxito del Heuriger lo que estropea este espacio típicamente austriaco, convirtiéndolo en un mero montaje:

Incluso un escenario parecería más real. $Y$ eso que las decoraciones aquí se usaban en el día a día. Las camareras también eran verdaderas como demostraban sus varices. Estaban aquí para servir cantidades de vino, algo de agua y un montón de carne.

Alrededor de las mesas de madera se estrujaban hombres y mujeres, turistas y aquellos vieneses que ya habían olvidado desde hace tiempo lo que constituye un Heuriger de verdad. Las grandes adelfas estaban puestas como siempre y el vino también se servía por lo general en garrafas y jarras pequeñas. Un Heuriger elegante en el barrio de Grinzing. Yo, personalmente huyo de estos locales como el diablo del agua bendita. El vino es malo y caro, el bufete aunque abundante, carece de las especialidades culinarias de los Heuriger auténticos, como Liptauer $^{14}$, morcilla casera, paté de hígado y, a lo mejor, jamón ahumado casero. Aquí el jamón viene de fábrica y se puede pedir desde el filete pescador hasta el Zwiebelrostbraten ${ }^{15}$ de todo, como si fuera un restaurante iTremendo! (Rossmann 2008b: 39)

El café vienés juega un papel casi protagonista al ser una presencia constante en la vida cotidiana urbana de Viena. Esta institución, algunos de cuyos ejemplares poseen una auténtica identidad, encuentra su lugar en cada barrio, imprimiéndole su carácter. Es otra vez Frank Tallis quien demuestra su amor por la Viena monumental llevando al lector a una experiencia completa del café. No solamente figuran dos de los grandes nombres como el Café Imperial y el Café Schwarzenberg, sino que además representa al detalle en qué consiste esta experiencia, que es todo un estilo de vida. El café es como un refugio que acoge al cliente, le salva de la

\footnotetext{
13 Desde el punto de vista de una mujer le da, en general, una nota negativa a la hospitalidad austriaca: "En Austria le solían dar la peor mesa a señoras sin compañía, en Nueva York el personal se ocupaba con especial amabilidad de una viajera solitaria. [...] Dormía profundamente hasta tarde, sólo eso era un regalo. En Viena había probablemente demasiado silencio de noche. Lo que necesitaba yo era Nueva York y no un psiquiatra" (Rossmann 2008: 128 y ss.).

${ }^{14}$ Dip de queso con especias (cfr. Wikipedia 2010).

${ }^{15}$ Asado de ternera con cebolla (cfr. Wikipedia 2010).
} 

ciudad como espacio plural, vol. 3, núm. 1, pp. 5-30. En: http://www.ucm.es/info/angulo/volumen/Volumen03 -1/articulos01.htm. ISSN: 1989-4015

intemperie y le arropa con camareros atentos; además pone a su disposición prensa nacional e internacional, colocada en un gran perchero donde cada periódico se sujeta con su tradicional orquilla de madera. $Y$, por supuesto, ofrece una amplia gama de cafés que estimula a los clientes, además de la opción de acompañarlos con pastelería vienesa (Tallis 2006: 4-5). Los interiores varían, el del Café Schwarzenberg, lujoso y acogedor con su bóveda de boiserie, contrasta especialmente con el exterior amenazador y ambiguo:

Era todavía media tarde, pero las lámparas de araña del café Scharzenberg [sic] ya estaban iluminadas. Fuera del local, una persistente llovizna había consumido la luz. Liebermann miró por la ventana, hacia la Scharzenberg Platz [sic], y observó la gran estatua ecuestre del príncipe Karl von Scharzenberg [sic], ahora un jinete pálido y fantasmal que emergía lentamente de la neblina. Más allá del príncipe espectral, apenas visible, se adivinaba el chorro de una fuente. (Tallis 2009: 91)

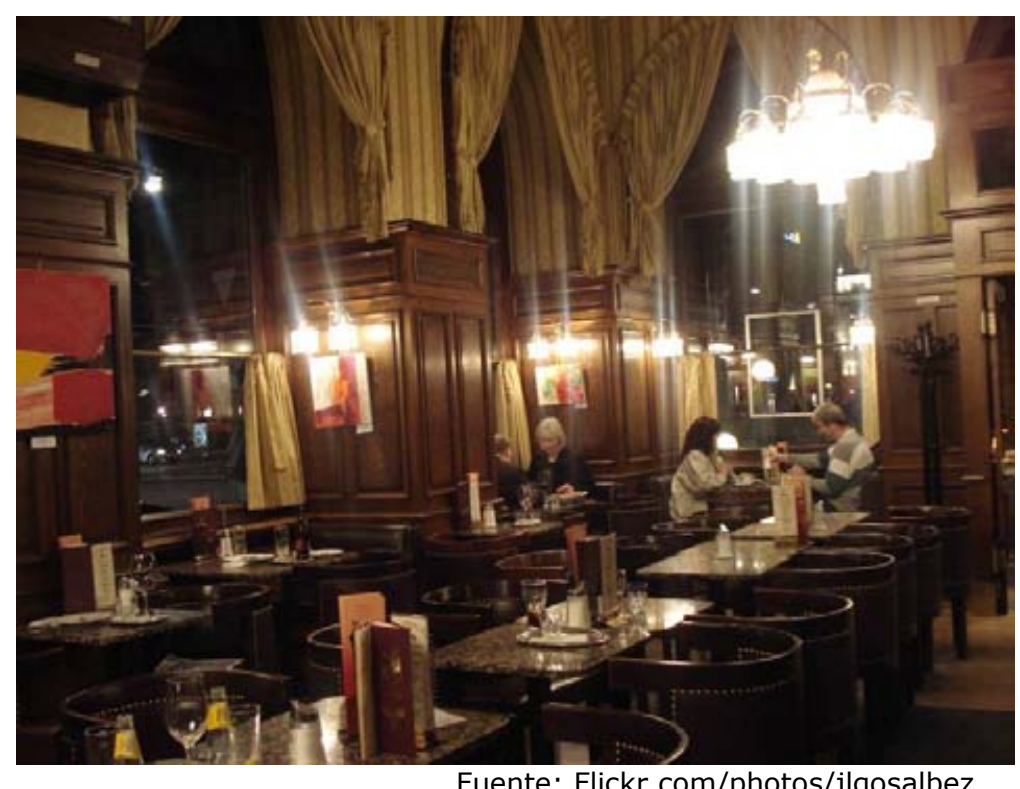

Figura 42. Interior del Café Schwarzenberg

Rossmann manda a su protagonista a otro gran clásico, el café del Hotel Sacher (Rossmann 2008b: 94). 
SCHATZMANN WILLVONSEDER, Martin (2011): "Escena del crimen: Viena. Una guía turístico-criminal desde el fin de siglo hasta nuestros días (II)" [en línea]. En: Ángulo Recto. Revista de estudios sobre la ciudad como espacio plural, vol. 3, núm. 1, pp. 5-30. En: http://www.ucm.es/info/angulo/volumen/Volumen03 -1/articulos01.htm. ISSN: 1989-4015

http://dx.doi.org/10.5209/rev_ANRE.2011.v3.n1.19500

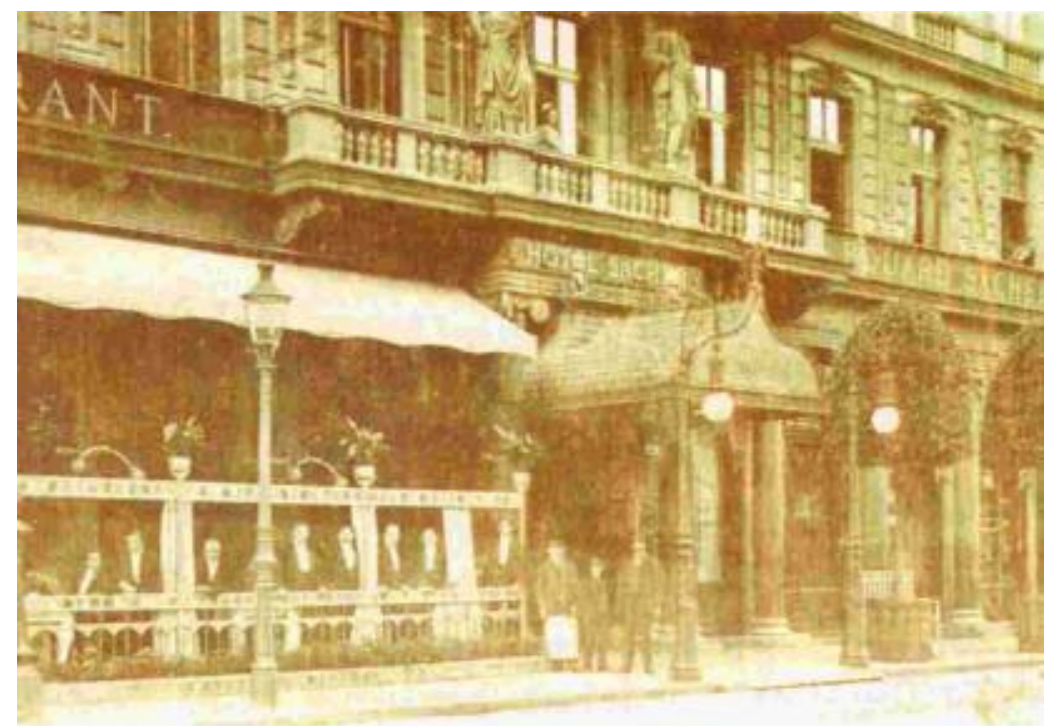

Figura 43

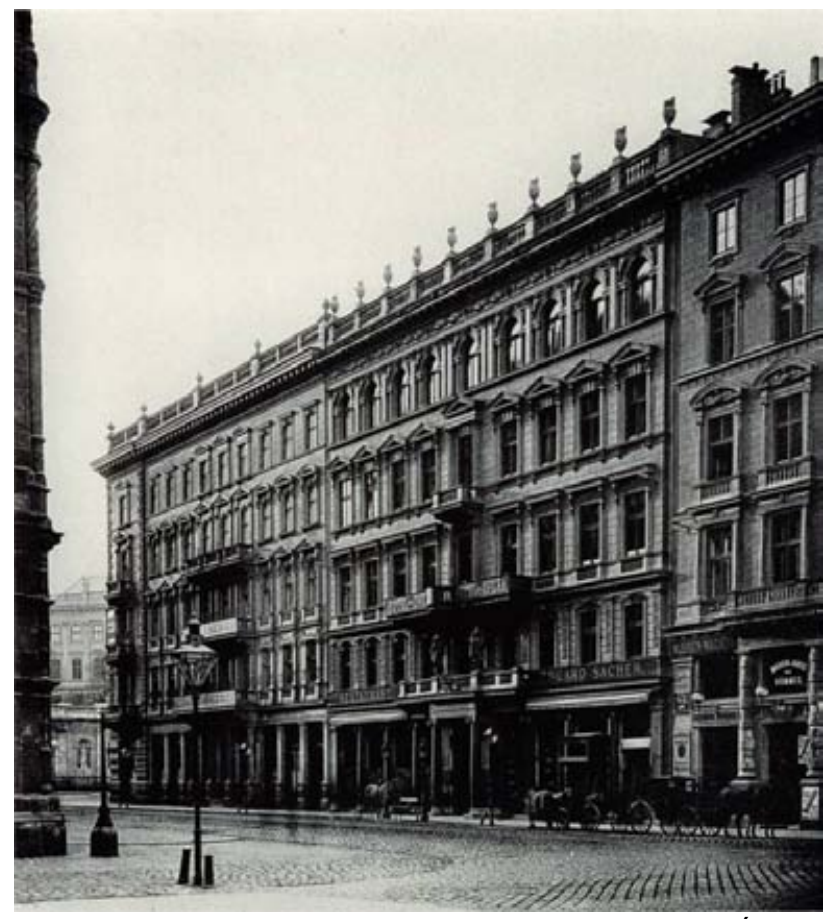

Fuente: Foro Dinastías

Figura 44. Hotel Sacher 

ciudad como espacio plural, vol. 3, núm. 1, pp. 5-30. En: http://www.ucm.es/info/angulo/volumen/Volumen03 -1/articulos01.htm. ISSN: 1989-4015

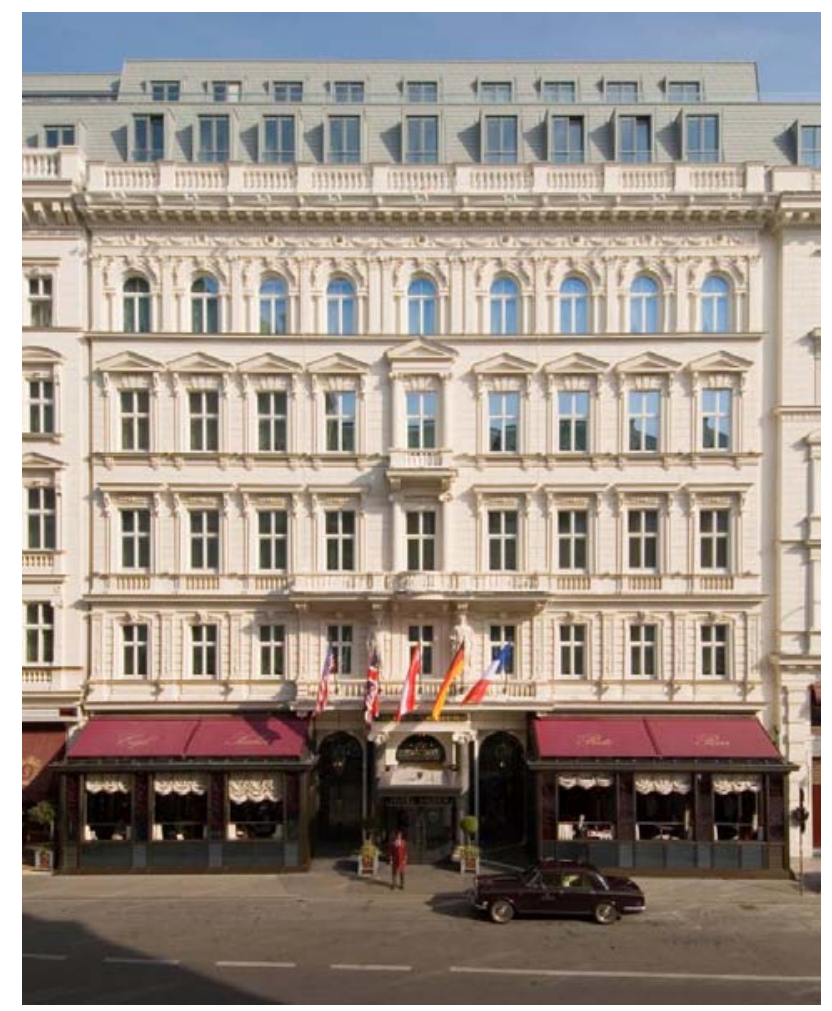

Fuente: Lions Club Wien Floridus

Figura 45. Fachada del Hotel Sacher en la actualidad

La diferencia entre estos autores es que en Rossmann solamente aparece el nombre de un café conocido, desvinculado de la trama. Tampoco transmite este placer que trasluce en las descripciones de Tallis, cuyos personajes visitan frecuentemente los cafés de cualquier categoría. No se trata de sitios de paso, sino que invitan a quedarse: "En Viena, el café había sustituido al teatro. Se podía aprender tanto de la naturaleza humana en el [café] Eisgovel [sic] como leyendo todas las obras de Goethe, Molière o Shakespeare" (Tallis 2009: 212).

Los cafés no siempre son los clásicos y elegantes del centro. Como un boceto de la monarquía multiétnica, aparece un café con propietario turco en caftán, y un par de húsares uniformados paseando fuera (2009: 101-102). Los cafés de Tallis (2006: 117-118) siempre tienen un ambiente característico:

Liebermann y Rheinhardt entraron en el Café Central por la sombría puerta trasera y recorrieron un estrecho pasillo que olía a café y también al amoniaco de los urinarios. Ascendieron unos pocos peldaños y penetraron en la gran sala con arcadas: un ruedo abovedado con columnas, envuelto en el zumbido de las conversaciones y el chasquido quebradizo de las bolas de billar. Una espesa nube de humo de los cigarrillos creaba una especie de asfixiante entoldado, bajo el cual se congregaba una apiñada multitud. Las mesas estaban bien espaciadas, pero la mayoría se 
SCHATZMANN WILLVONSEDER, Martin (2011): "Escena del crimen: Viena. Una guía turístico-criminal desde el fin de siglo hasta nuestros días (II)" [en línea]. En: Ángulo Recto. Revista de estudios sobre la ciudad como espacio plural, vol. 3, núm. 1, pp. 5-30. En: http://www.ucm.es/info/angulo/volumen/Volumen03 -1/articulos01.htm. ISSN: 1989-4015 http://dx.doi.org/10.5209/rev_ANRE.2011.v3.n1.19500

encontraban rodeadas de grupos de espectadores, que criticaban abiertamente los movimientos de una partida de ajedrez o animaban a los jugadores de cartas a incrementar sus apuestas. (Tallis 2009: 249)

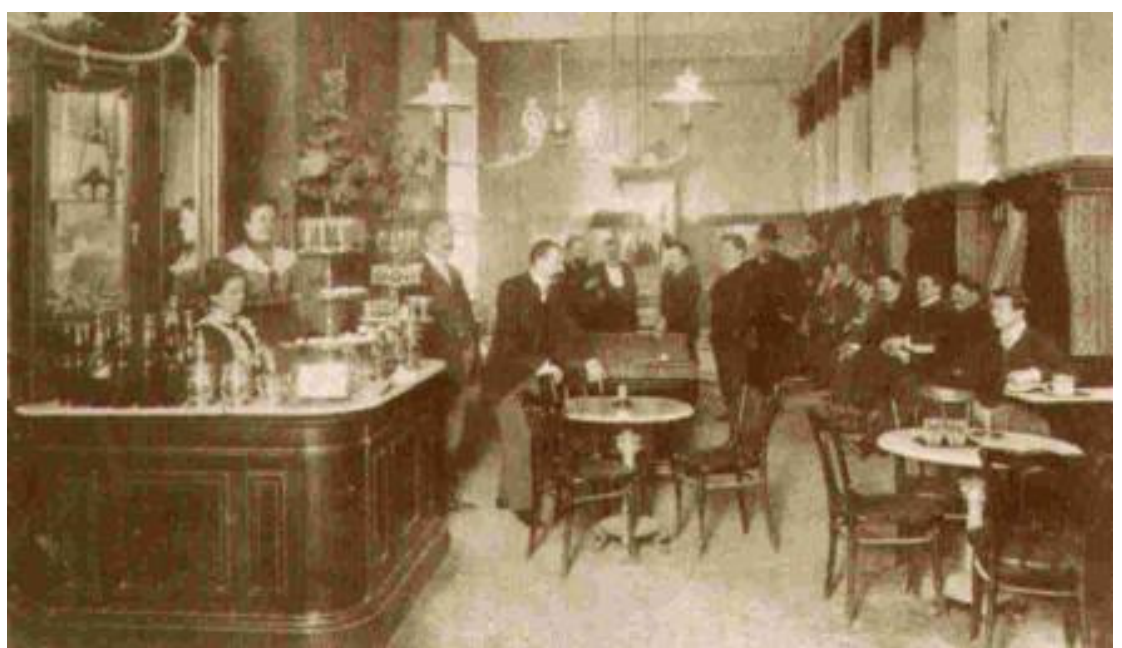

Figura 46. Café Sperl

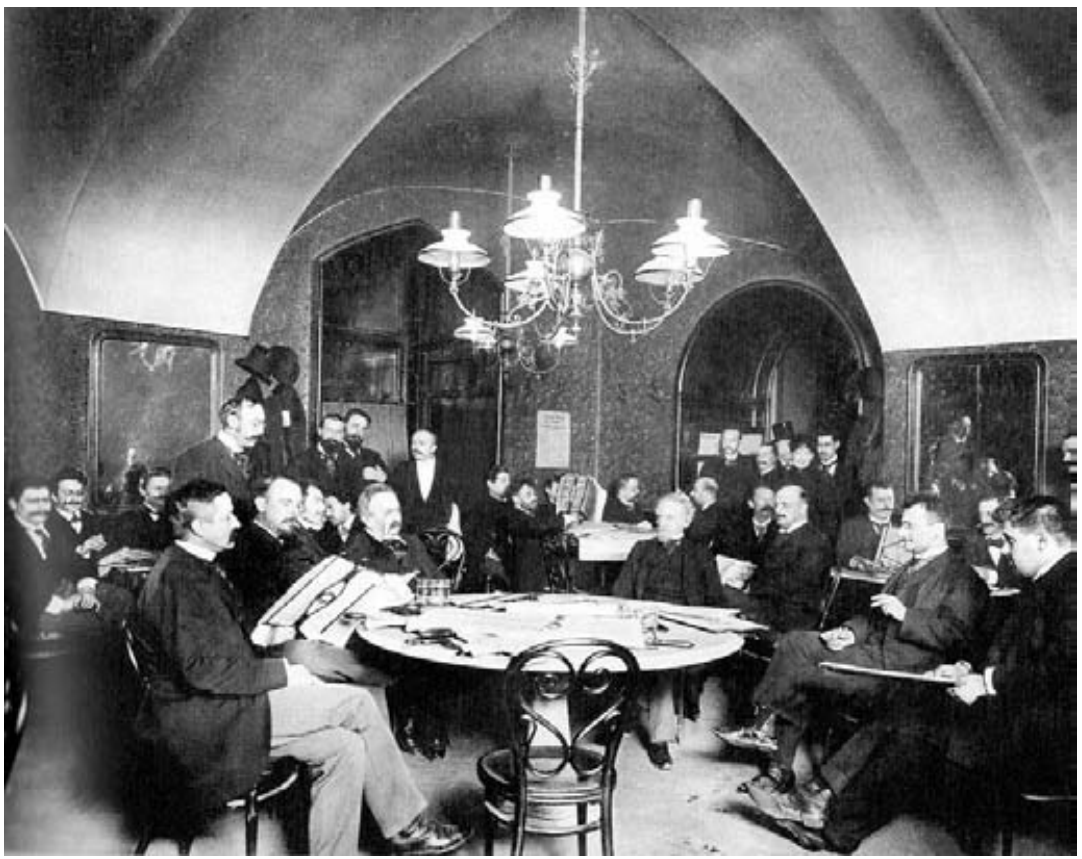

Figura 47. Café Griensteidl hacia 1897

La versión de Haas, por el contrario, es sarcástica, el anti-cafévienés, una modernización cutre sin clientela. Todo el ambiente tiene un aire de sala de espera para el infierno: 
Aparte de ellos dos y el camarero solamente había otro cliente, una señora en chándal, que se trabajaba la máquina tragaperras. A pesar de estar casi vacío el local apestaba tanto a humo de cigarrillos que Brenner pensó por un momento que este cantante italiano melindroso sonaba todavía más ronco aquí de lo normal, y que en cualquier momento le daría un ataque de tos. (Haas 1998: 54)

Los locales ilustran especialmente bien el contraste entre la visión clásica del inglés Tallis -lugares acogedores donde se puede pasar el tiempo de forma agradable- y la versión de los autores austriacos Rossmann y Haas, que transforman los locales en escenarios donde se valora más la cantidad que la calidad, o en lugares que se caracterizan por lo contrario de lo que uno esperaría de un café vienés. Rafelsberger en cambio se asemeja más a Tallis y describe los locales actuales como acogedores. Una tendencia muy popular digna de mención es la transformación de museo en local, en el caso del recinto de arte MuseumsQuartier:

En el enorme patio del arenal había cientos de personas tumbadas en esculturas de formas extrañas, en bancos y escaleras, tomando el sol, leyendo, comiendo, escuchando música, charlando. En ninguno de los tres locales que estaban a la vista Petzold descubrió una mesa libre. Le encantaba este sitio. Se habían restaurado los antiguos establos de la casa imperial con cuidado, combinándolos con arquitectura moderna. Ahora ofrecían hogar y escenario para museos, arte contemporáneo, jóvenes iniciativas culturales y creativos. Obviamente también había locales acogedores. (Rafelsberger 2009: 139) 


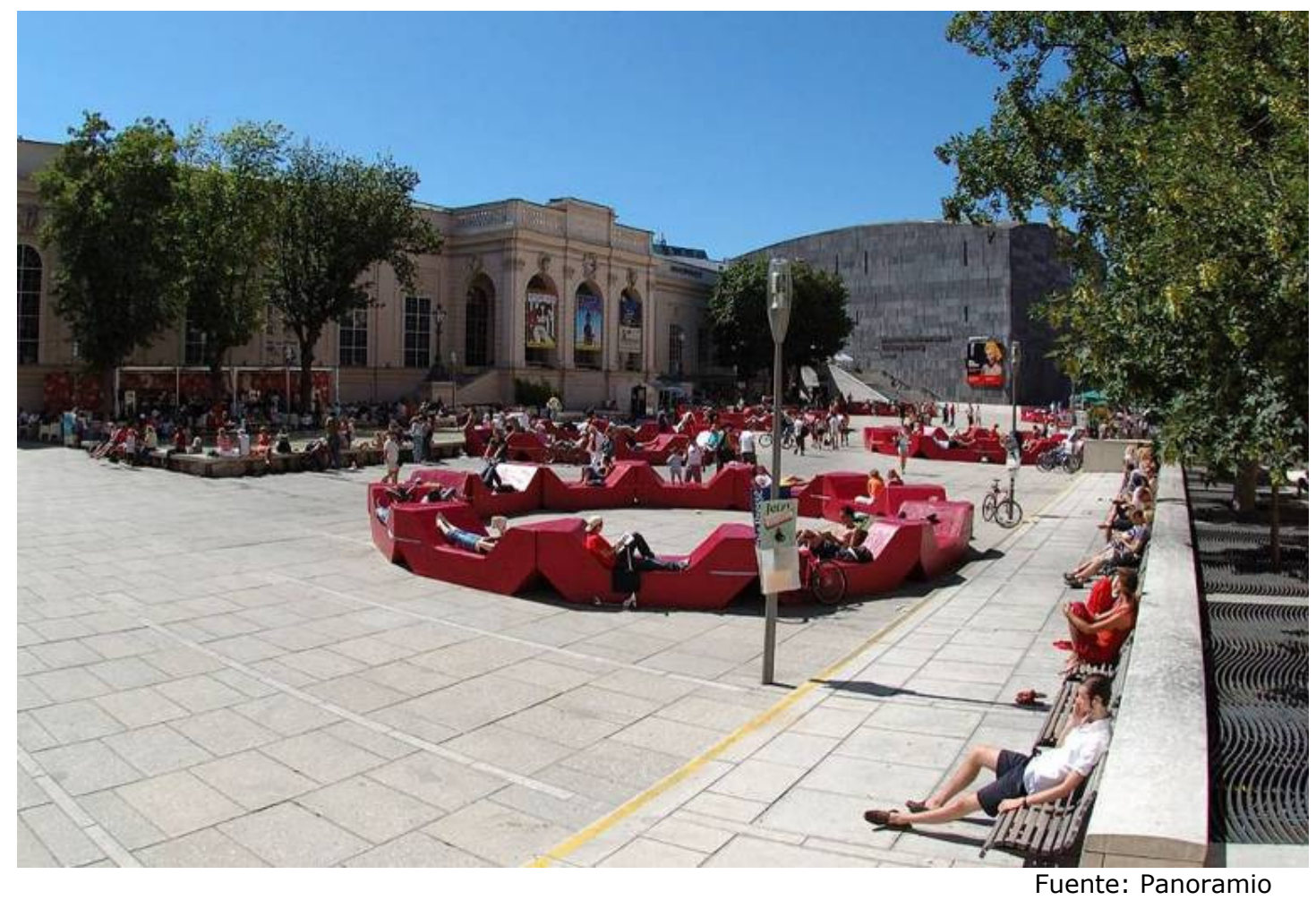

Figura 48. Museumsquartier

\section{Hospitales y medicina}

Otro tema une a los cuatro autores a Viena: la medicina y los hospitales, que recuerdan su importancia como capital de las ciencias, especialmente la medicina. Aunque las cuatro visiones son diferentes, coinciden sin embargo en la idea de presentar estos espacios como lugares de tránsito hacia lo desconocido. Ya sea este tránsito científico, físico o entre géneros, pero en cualquier caso a lo desconocido. Como personaje destaca la figura del Profesor Freud, al que Tallis asigna un papel como mentor y consejero de su protagonista. Pero detrás de una imagen campechana y abierta del profesor Freud van surgiendo las sombras del antisemitismo omnipresente en la Viena de la época. Estas sombras nunca cobran protagonismo, pero siempre acompañan.

Esta visión de principios del siglo XX (Tallis 2006: 394) contrasta con la de finales del siglo en Freudsche Verbrechen. Berggasse 19 (figura 49) ya no es la dirección actual sino la del Museo de Freud, el cual por cierto es mejor conocido por los turistas que por los propios austriacos. 


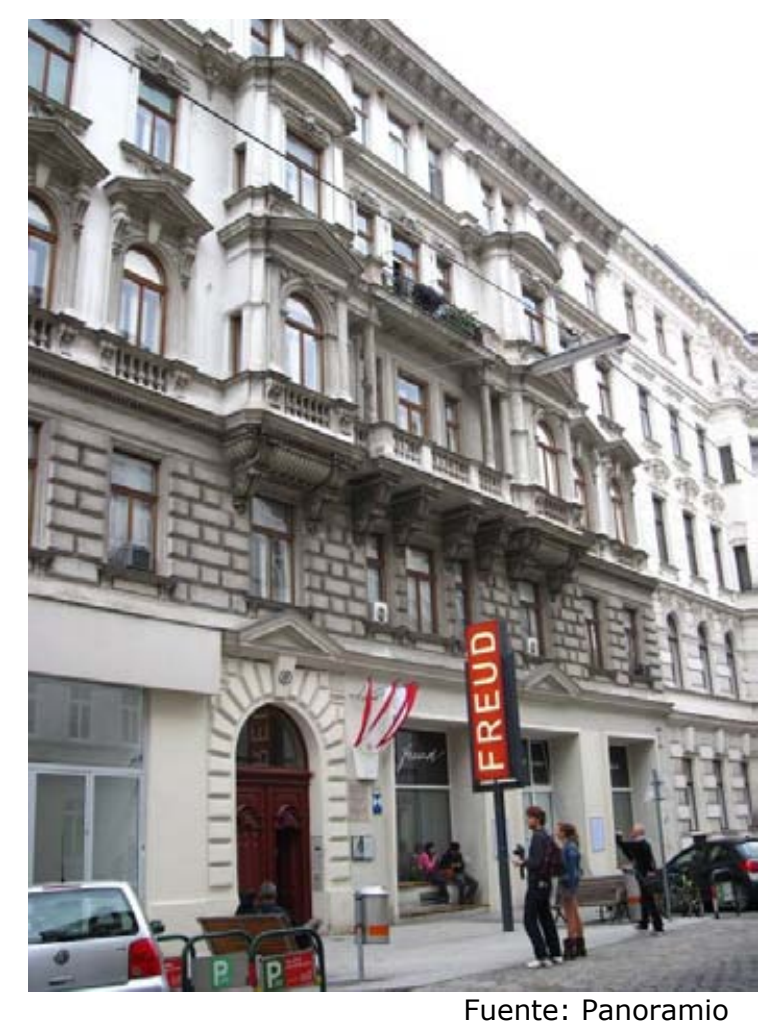

Figura 49. Museo Freud, en Berggasse 19

Casi un siglo después del antisemitismo pre-nacionalsocialista, la trama tematiza sus consecuencias y el papel de Austria en la II Guerra Mundial. Ambos libros vinculan los asesinatos con el antisemitismo, sin embargo es un tema aplicado en dosis pequeñas que Rossmann incrementa poco a poco.

La importancia de la medicina desvela el fondo profesional de Frank Tallis. Los hospitales y la universidad médica de Viena encabezaban la ciencia de la época. Son tratados por los autores como lugares cuyo oscuro límite sin definir tiene el potencial de cambiar de dimensión a los que se aventuren a intentar averiguarlo. De todas partes venían estudiantes para aprender en Viena, donde las más diversas teorías y novedosas técnicas rivalizaban. El protagonista, Dr. Liebermann, alumno de Freud, trabaja en la exploración del inconsciente y emplea la hipnosis con éxito (Tallis 2009: 106; 2006: 76). Son estas prácticas, todavía muy discutidas y revolucionarias, las que se van mostrando más eficientes. La otra vertiente, la electroestimulación, se describe en la mejor tradición gótica, con demostraciones universitarias de tratamientos violentos de descargas eléctricas y despachos parecidos a una Wunderkammer médica con malformaciones en formol, aparatos eléctricos y baterías en forma de ataúd (Tallis 2006: 204-205; 2009: 245). Esta técnica parece al lector actual ciencia de otro siglo, mientras que la psicología aplicada por Liebermann suena muy moderna. 
SCHATZMANN WILLVONSEDER, Martin (2011): "Escena del crimen: Viena. Una guía turístico-criminal desde el fin de siglo hasta nuestros días (II)" [en línea]. En: Ángulo Recto. Revista de estudios sobre la ciudad como espacio plural, vol. 3, núm. 1, pp. 5-30. En: http://www.ucm.es/info/angulo/volumen/Volumen03 -1/articulos01.htm. ISSN: 1989-4015

En la descripción de los edificios se mezclan el afán por el detalle de Tallis con su interés profesional:

Cuando llegó al Josephinum -el antiguo Colegio Militar de Cirugía y Medicina- [figura 50] se detuvo y vio, por las altas barandas, una representación imponente de la feminidad: una enorme escayola de Higinia, la diosa de la salud. Era una de las pocas figuras clásicas de Viena que reconocía. La diosa se alzaba, dominante, sobre Liebermann, aferrando con su poderosa mano el cuello de una enorme serpiente que se le enroscaba por el brazo y le caía sobre el hombro en una serie de movimientos decrecientes. La diosa alimentaba a la gran serpiente, y por eso simbolizaba las dobles virtudes de la fuerza y la compasión. Cuando la luz del sol se filtró entre algunas nubes bajas, sus ojos se convirtieron en espejos de peltre. (Tallis 2009: 303)

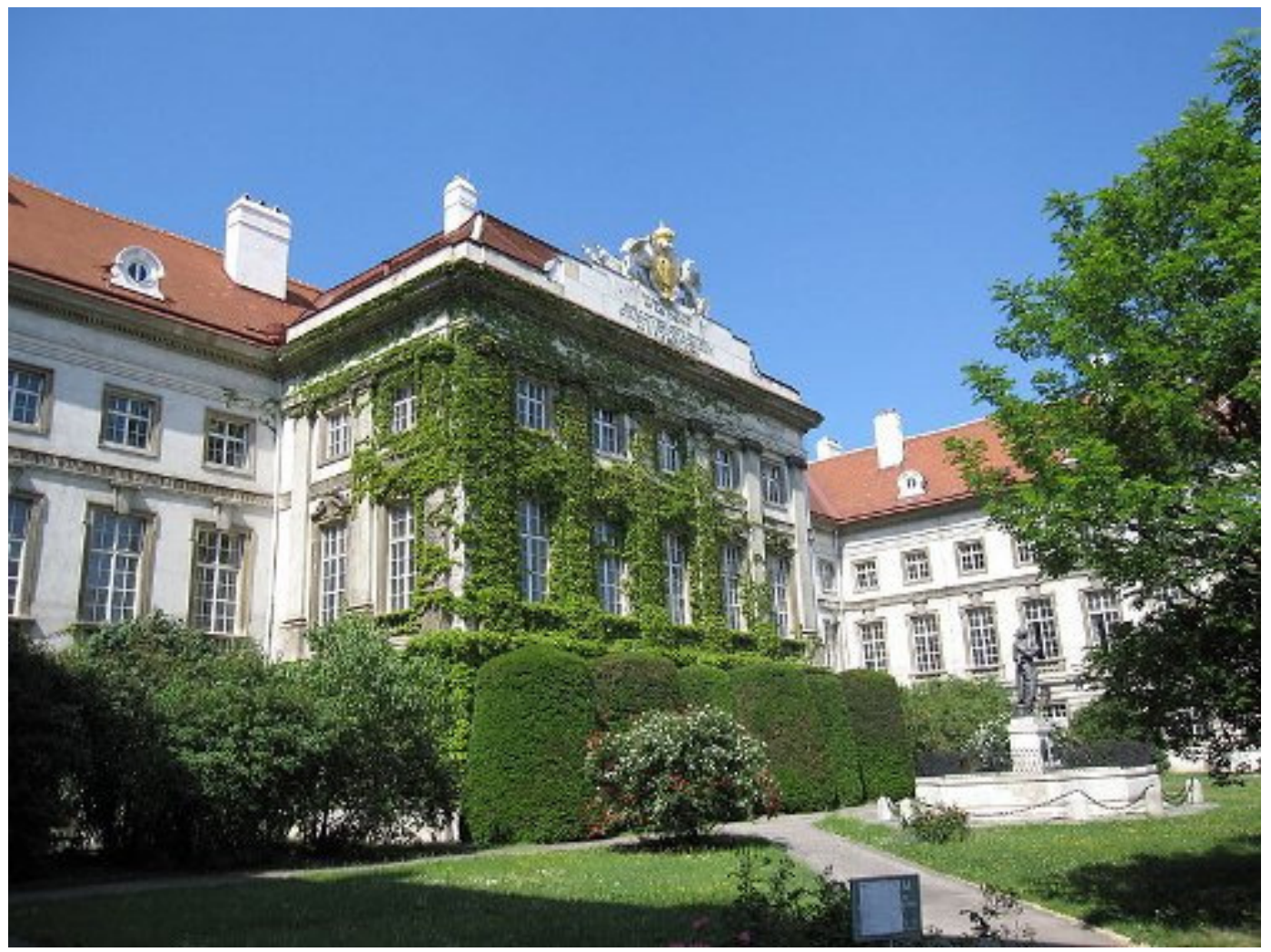

Figura 50. Josephinum

Esta imagen contrasta con la visión moderna de la medicina en Viena, representada por las enormes torres del Hospital General. 
SCHATZMANN WILLVONSEDER, Martin (2011): "Escena del crimen: Viena. Una guía turístico-criminal desde el fin de siglo hasta nuestros días (II)" [en línea]. En: Ángulo Recto. Revista de estudios sobre la ciudad como espacio plural, vol. 3, núm. 1, pp. 5-30. En: http://www.ucm.es/info/angulo/volumen/Volumen03 -1/articulos01.htm. ISSN: 1989-4015 http://dx.doi.org/10.5209/rev_ANRE.2011.v3.n1.1950]

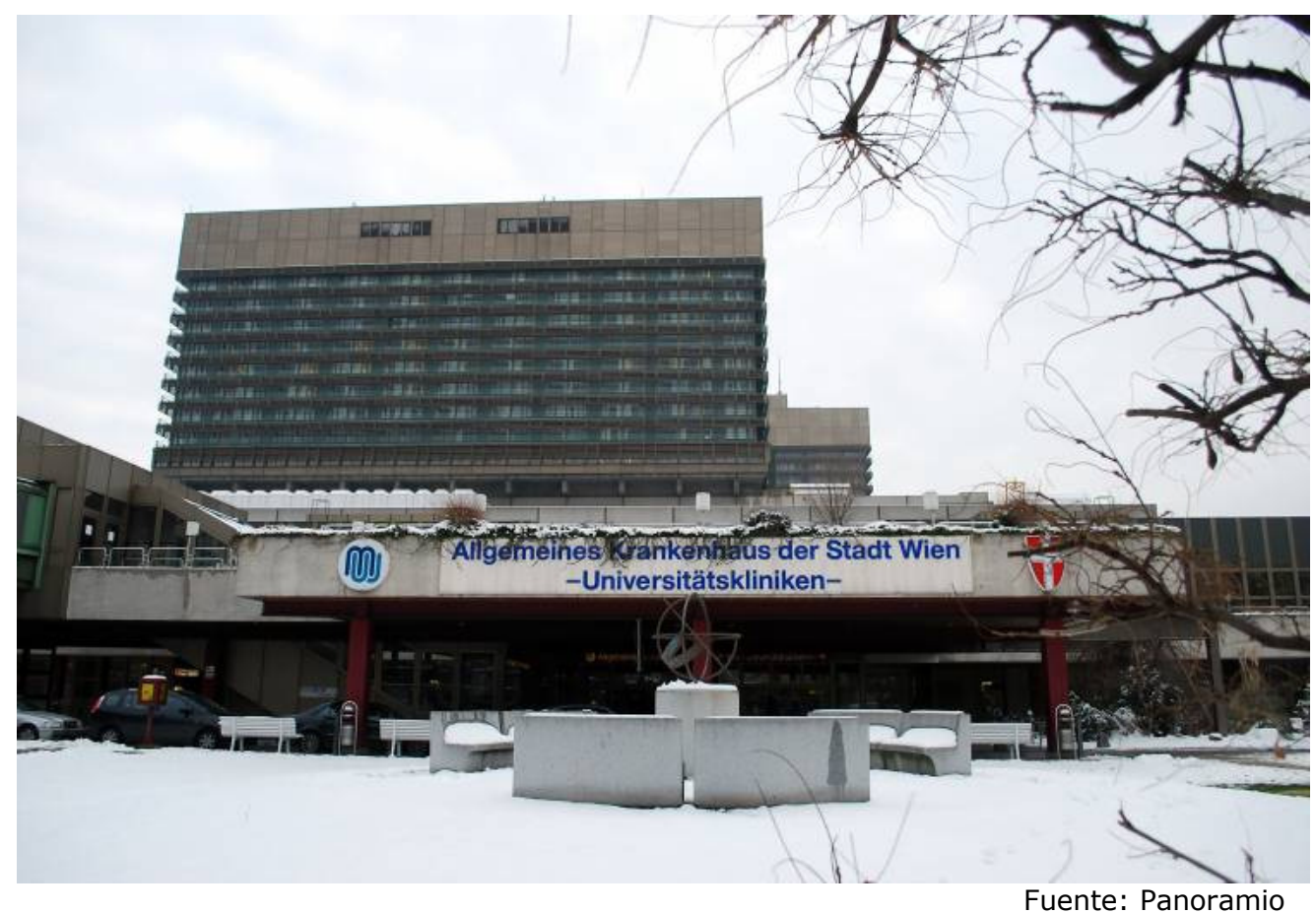

Figura 51. Entrada al Hospital General AKH

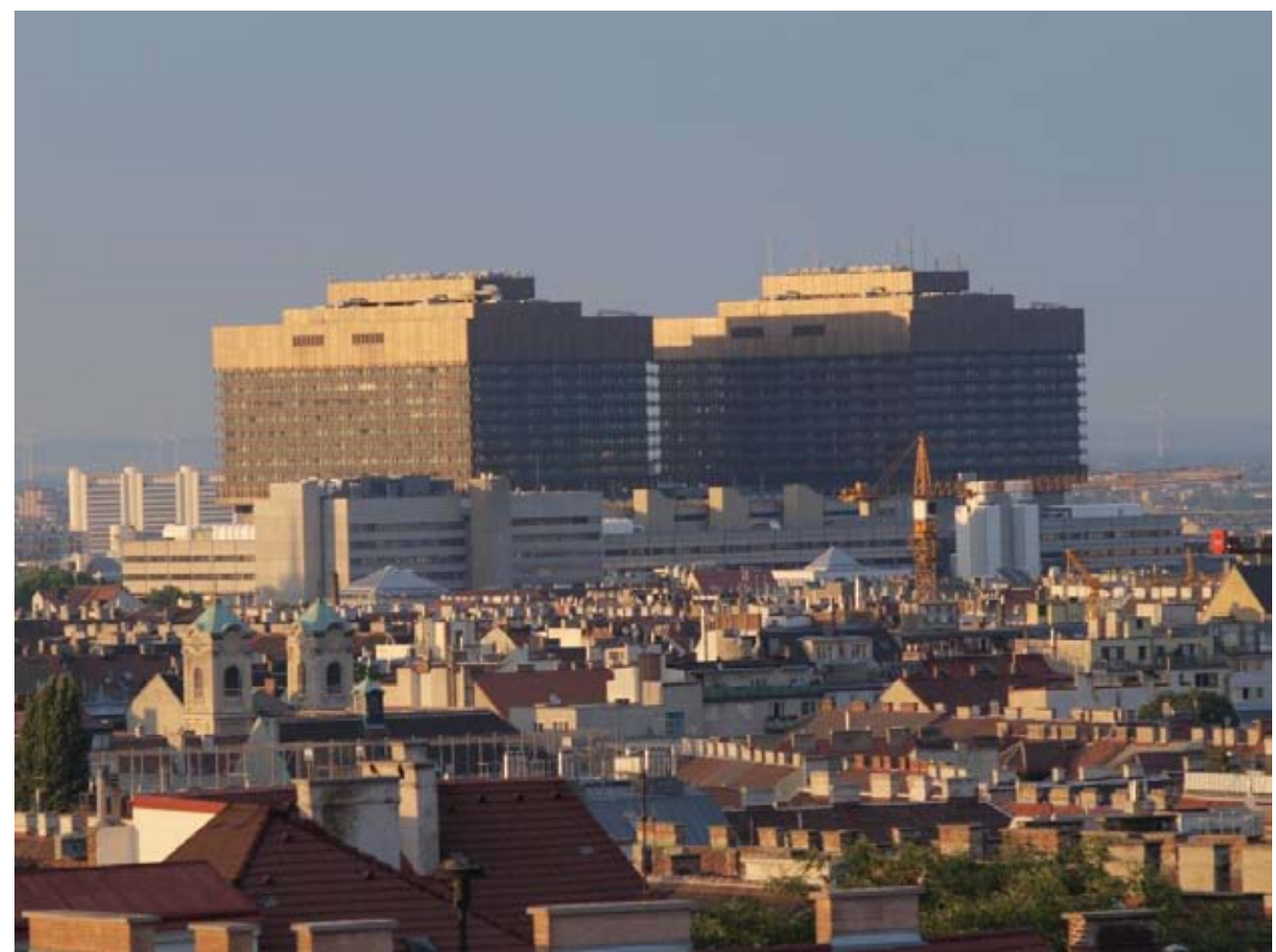

Figura 52. Las torres del Hospital General

Fuente: Panoramio 


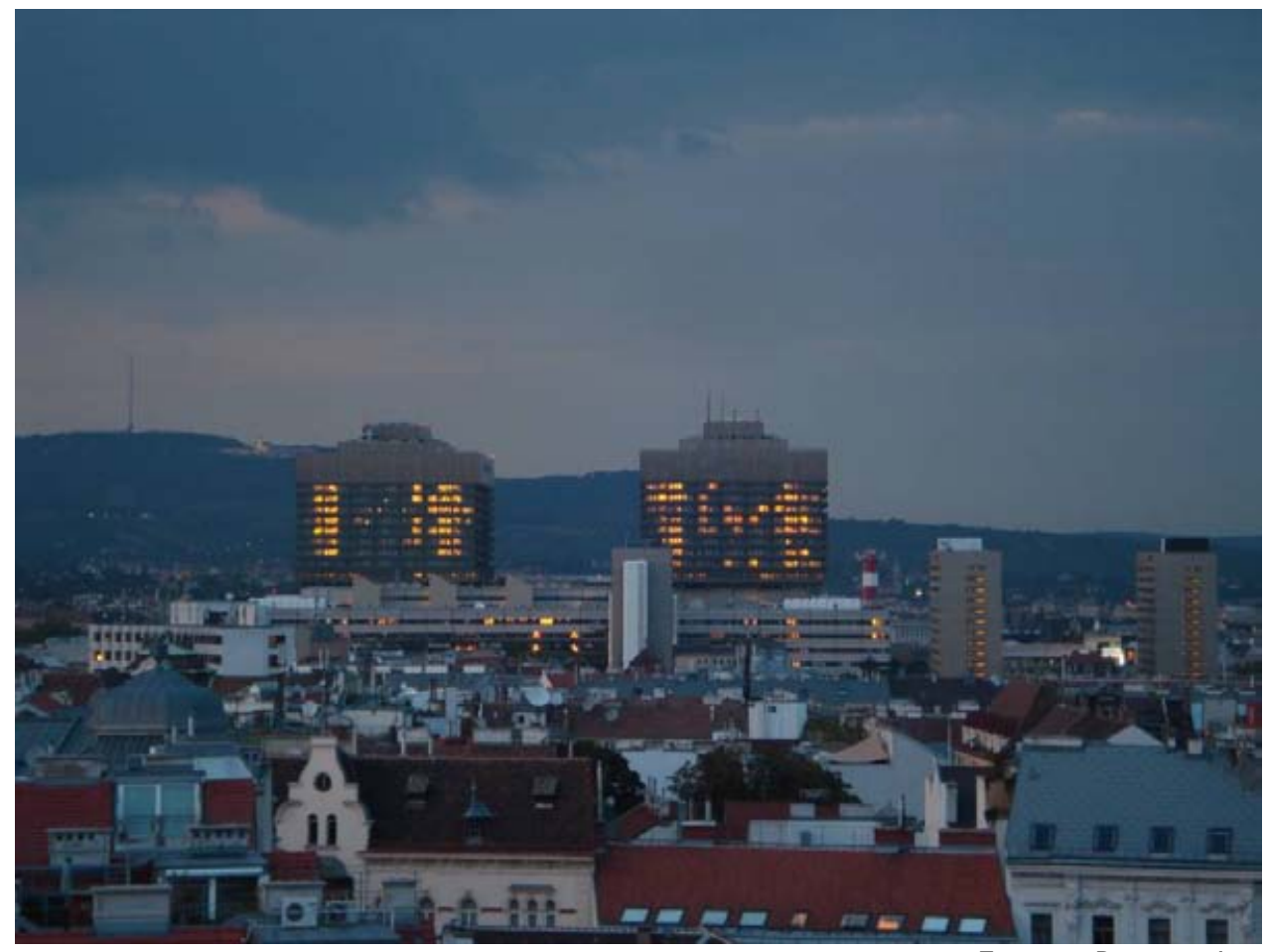

Figura 53. Hospital General iluminado

La protagonista de Rafelsberger (2009: 15) resume su impresión así: "Petzold odiaba todos los hospitales, pero los bloques gigantescos del Hospital General en el distrito nueve en especial" (figura 52). Sin embargo se verá obligada a reposar en estas torres como paciente y volver al trabajo todavía en bata cuando el hospital se convierte en el lugar del crimen. El intento de asesinato de una víctima y testigo que desemboca en una persecución entre batas blancas trae la violencia al hospital. A este caos se suma el aspecto de la policía vestida de paciente, que a su vez causa trastornos (Rafelsberger 2009: 305).

Wolf Haas, por su parte, se muestra subversivo una vez más, oponiéndose a esta imagen clásica de la medicina. Komm, Süßer Tod está escrito desde la perspectiva de los conductores de ambulancia. Pero es más que un cambio de perspectiva social, la reputación de salvadores desinteresados que sufre una demolición. Los hospitales de Viena se convierten en el campo de batalla de dos empresas de ambulancias que recurren a cualquier método para conseguir pacientes, o sea clientes. A un nivel personal los conductores arriesgan vidas en vez de salvarlas, conduciendo a toda velocidad por Viena. Pero al recoger un supuesto órgano en el hospital general, la carrera resulta tener su meta en un puesto de comida rápida delante del hospital. Todos los valores sufren una transformación y los pacientes pagan el precio. 
En la larga lista de hospitales (Wilheminenspital, Barmherzige Brüder, AKH...) que van formando un propio mapa de Viena, destaca el Franz-Josef-Spital, obviamente para ironizar otro símbolo de Viena:

\begin{abstract}
Ahora bien, no lo confundas [el hospital Franz Josef] con la estación Franz-Josef donde Brenner no había encontrado al vagabundo en su momento. Es que la estación está justo en el otro lado de la ciudad, lo del mismo nombre solamente es una coincidencia. $O$, a lo mejor no tanta coincidencia, porque Francisco José sí que es un poco el emperador local en Viena. (Haas 1998: 207)
\end{abstract}

\title{
7. Viena, antisemitismo, nazismo
}

El delicado tema del antisemitismo, del pasado nazi y cómo se trata aquel lastre histórico es un lugar común entre los autores elegidos, un tema presente y actual que se refleja en cada autor a su manera. Viena aparece invariablemente como escenario por excelencia de los mayores pecados del siglo XX. Al tratarse de una novela de época, Mortal Mischief trata el tema de la Viena judía como actualidad y lo introduce de manera natural a través del diálogo entre Liebermann padre y Liebermann hijo. El vínculo entre la familia y el barrio de Leopoldstadt es determinado como centro de la comunidad judía sin dar más explicaciones. Lo mismo se vincula la ciudad con la sociedad judía indirectamente, a través de nombres, negocios, oficios y detalles culturales. Entre otros aparece el profesor Freud contando chistes judíos a pesar de tener problemas en la universidad por ser ése su origen (Tallis 2006: 110). Asimismo figura el alcalde antisemita de la época, Karl Lueger, en compañía de uno de los sospechosos del crimen (Tallis 2006: 168), lo cual ya indica que el antisemitismo va a tener un papel relevante en el desenlace de la novela. Esta manera de dejar caer indicios, como las alusiones antisemitas durante la visita al friso de Beethoven en la Secesión (Tallis 2006: 206-207), va subiendo de tono durante la novela, hasta llegar a chismes terribles sobre rituales sangrientos de los judíos (Tallis 2006: 390). Así refleja muy bien la presencia del antisemitismo en la sociedad, que se infiltra poco a poco como un veneno aumentando la dosis (2006: 440) hasta el final letal que, en la novela de Tallis, proyecta su amenaza hacia el futuro:

Sobre las colinas lejanas, un claro entre las nubes dejó lanzar una ojeada al sol del ocaso. Una neblina rojiza se extendía por el horizonte y, por un momento, el cielo adquirió la textura y el color del bronce batido. Bajo ese cielo vengativo, Viena semejaba una ciudad bíblica, una extensión decadente, lista para el castigo merecido y el lamido purificador del fuego sagrado. (Tallis 2009: 360)

Para los autores austriacos es indudablemente un pasado que no se puede olvidar. En las novelas de Wolf Haas no llega a ser un 
tema dominante que cobre importancia en la trama. Sin embargo menciona con mucha soltura y como de paso el pasado nazi de los personajes secundarios o algunas expresiones xenófobas, sin darle más importancia (Haas 1998: 45). De esta manera da -de una forma parecida a Tallis- un aspecto de naturalidad a esa presencia real, a esa amenaza oscura del pasado nazi. Rossmann, en cambio, dedica todo un libro a este tema, más concretamente al escándalo de los bienes judíos robados por los nazis durante el holocausto, un tema de hecho muy actual hasta el día de hoy. Freudsche Verbrechen, por otra parte, resucita con unas cartas antiguas la huida de una familia judía después del Anschluss, en 1938. En este espejo del pasado los comentarios xenófobos y nacionalistas actuales de diferentes figuras resultan más chocantes (Rossmann 2008a: 140-150). Esta línea fina entre patriotismo y nacionalismo que define a Austria también provoca quebraderos de cabeza en su novela, que gira en torno al mundillo de la música folclórica:

Populismo diseñado para unir Austria. Pseudo-comunidad. Alzada por políticos con y sin traje folclórico. Lo que no era "austriaco", era ajeno, se estilizaba hacia una amenaza. Así se podía manipular el ambiente, con eso se podía azuzar a la gente. iSe puede todavía! La excursión al mundo de la música folclórica no había precisamente fortalecido mi patriotismo. (Rossmann 2008a: 191)

Rafelsberger también paga su tributo a El tercer hombre sin necesidad de referirse a la noria. El abanico de crímenes de la actualidad en Menschenteufel tiene su raíz en aquella Viena destruida de la postguerra, del mercado negro y del trato entre vieneses y ocupantes. Sin convertir la xenofobia y el nacionalismo en temas principales aparecen sin embargo como partículas de chapapote que polucionan su entorno una y otra vez. Para una nación tan dependiente del turismo como Austria, conocida por su imagen acogedora y cultural, es una mancha fea, visible y difícil de borrar. Lo llamativo es que todos los autores investigados nutren sus tramas de aquel período negro, transmutando así la bienvenida de Viena con una sombra amenazadora, convirtiendo la antigua capital del Imperio Austro-Húngaro en un espacio en el que las energías de distinto signo aún no se han asentado. 


\section{Conclusión: Viena y sus torres oscuras}

Es una ciudad muy hermosa -dijo Bruckmüller-, ¿no está de acuerdo, doctor? -pero antes de que Liebermann le respondiera, volvió a hablar-: No, supongo que no está de acuerdo, siendo vienés... Me atrevería a decir que hasta admitirlo ofendería su sensibilidad urbana. Seguro que prefiere criticar con cinismo sus excesos. (Tallis 2009: 361)

Probablemente sea ésta la cita que mejor contraste la perspectiva de Viena vista desde fuera y desde dentro. Con estas palabras Tallis nos da además a entender que es totalmente consciente tanto de su posición como extranjero, como de la reputación de los vieneses de criticar su ciudad.

El autor británico no sólo muestra ser conocedor de la ciudad sino también de la época. Disfruta dando vida a la Viena monumental, a su exuberancia, su glamour y su cultura. Su amor al detalle se extiende más allá de la descripción arquitectónica, se mete en los interiores, descubre su diseño y -guiado por el protagonistaobserva toda la cultura. Sabe recrear la época y la capital multicultural y multinacional con su importante comunidad judía sin acallar sus problemas sociales. Diferencia los barrios y anima la vida en la calle, el tráfico, las luces y los olores. Pero es muy consciente de estar presentando una visión unilateral e incompleta. No es casualidad que el asesino defienda la belleza de Viena y la visión de una ciudad menos multinacional, menos multiétnica ante el protagonista. Este contraste entre la belleza arquitectónica y la amenaza creciente es lo que vuelve a Viena un lugar tan ambiguo en la novela de Tallis. En ella, las tendencias pangermánica y antisemita son tan históricas como su arquitectura, y encaminarán a Austria hacia el capítulo más oscuro de su historia. Estos temas se presentan con resultados diferentes en las obras de los otros tres autores austriacos. En las obras de estos últimos y a diferentes niveles sociales se confirma la actualidad de las expresiones xenófobas, en boca de políticos populistas 0 en motivos criminales. Su materialización más visible es probablemente la herencia arquitectónica militar en Wie die Tiere, las torres de defensa antiaérea que siguen sobresaliendo de la silueta de la ciudad actual. Para Haas son la encarnación de los problemas psíquicos que siguen atormentando la mente común de la sociedad de hoy.

Esta sombra del pasado junto a la gloria perdida de la monarquía marcan la mentalidad de los vieneses o, en palabras de Eva Rossmann (2008a: 64): "Viena era para mí la mezcla perfecta entre metrópolis y provincia -iy punto!".

La capital de Austria da la sensación de aprovechar sus restos gloriosos del pasado, que ya han perdido su valor original en una ciudad que envejece: "Viena es una ciudad de la que se dice que es 
especialmente buena para morir. Bien puede ser, pero personalmente encuentro que Viena también es especialmente buena para pasear" (Haas 1998: 162).

Los autores austriacos coinciden con la cita de Tallis. Para ellos su capital no parece haber vuelto al corazón de Europa -como dice el texto del himno nacional- después de la caída del telón de acero. Más bien sigue marcada por el carácter provinciano (Rossmann 2008a: 40-41), la burocracia y el enchufismo (Rossmann 2008a: 86), vendiendo una farsa con los restos visibles de épocas más ilustres. Todo lo "real" se opone a la imagen oficial de la capital.

Desde un punto de vista urbanístico, resulta que todos los libros investigados comparten una serie de elementos característicos que van conformando la imagen de Viena. El peso de la trama se desarrolla en los espacios públicos de la ciudad, dando así fe de su vitalidad y su representatividad. Mientras que la conocida Viena monumental cobra vida en la novela de Frank Tallis, los autores austriacos la aprovechan solo para subrayar el carácter tópico y la visión turística, hasta cierto punto hoy irreal, de la ciudad fin de siglo. Más bien buscan anti-monumentos para oponerlos al esplendor nostálgico. Es una Viena igual de visible y presente, que carece del foco de atención pública no-austriaca.

Entre los monumentos que se prestan especialmente bien a una transformación destaca la noria en la feria de atracciones. Hoy un símbolo nostálgico, lleva ya la casi insalvable marca de El tercer hombre. Esta imagen aprovechable da un vuelco más en la novela de época de Tallis. En vez del contraste entre tanta destrucción y el parque de atracciones, aparece todo en plena actividad. Aquí la noria es una novedad espectacular y se va convirtiendo sucesivamente a lo largo de la trama en consulta de médico, en confesonario y finalmente en lugar del crimen.

Especialmente los parques resultan ser lugares muy recurrentes donde se une lo imperial con los anti-monumentos, y que, además de ser pulmones verdes, funcionan como alma y metáfora de la ciudad. Todas las novelas desarrollan parte de su trama en este marco, desde situaciones privadas como los paseos románticos, hasta la delincuencia, la persecución y la detención de los culpables. Destacan los parques Prater y Augarten, que pierden su función recreativa para convertirse en lugares de muerte, en campos de batalla o en cementerios. Pero también el parque del Be/vedere adquiere gradualmente un aspecto gótico y ambiguo. Las estatuas prácticamente cobran vida y trasladan el paseo de los enamorados a un país de las maravillas grotesco.

Los museos curiosamente, tan presentes en la imagen de la ciudad, no tienen ningún papel relevante entre los monumentos. Solamente, vinculada con el personaje del Profesor Freud, aparece la dirección Berggasse 19. Lo que hoy día es su museo vuelve a ser 
casa y despacho en la novela de época. Eso se debe probablemente a su posición como monumento intelectual y científico de Viena, ya que la medicina es un tema recurrente en las novelas. Los hospitales y los servicios médicos juegan un papel especial, y la posición de la ciencia sin duda marcó la Viena fin de siglo. La red de hospitales y las ambulancias recrean la actualidad, donde resalta el Hospital General, el $\mathrm{AKH}$, una mole arquitectónica de dos torres oscuras que sobresalen sobre la silueta del distrito 8. A juzgar por la visión crítica de Wolf Haas se detecta un paralelismo entre esta pareja de torres y las dos torres antiaéreas del otro libro tratado aquí. Ambas construcciones destacan por su color y su tamaño, son antimonumentos característicos de la ciudad y ambos tienen una carga de crítica. En el caso del hospital, se trata de una serie de escándalos en torno a su construcción en la realidad, y de los abusos por parte de la administración y el trato a los pacientes en la ficción. Así, una institución diseñada para salvar vidas humanas resulta ponerlas en peligro y convertir a los pacientes en mercancía y víctimas; mancillando una vez más la reputación tópica que tienen los extranjeros de Viena como capital histórica de la medicina.

Otro punto común de los libros tratados es el papel de los locales típicos de Viena. Otra vez es Tallis quien presenta con entusiasmo la cultura del café vienés al detalle. Contrasta los grandes clásicos con una serie de cafés más humildes, de diferentes barrios y etnias de la ciudad. A tanto tópico vienés Haas opone el anticafé y se regodea en la descripción de los ambientes espesos de las tabernas. Rossmann en cambio se centra en otro original vienés, el Heurigen. Este tema le permite criticar la transformación del humilde pero genuino local de vino en un restaurante turístico con bufet y diseño rústico. En resumen, queda la impresión de que lo típico se ha convertido en un mero escenario, pura tramoya espiritual, y que la realidad ha perdido autenticidad.

En el camino hacia la resolución del crimen, la persecución de pistas y sospechosos, se perfila notablemente la diferenciación de los distritos de Viena. Todos los autores dan mucha importancia al aspecto social y económico de los barrios. Estos cambian según la época en la que está situada la trama, pero la oposición de barrios pobres y barrios ricos resultó ser un punto muy importante para los cuatro. Aunque los barrios pobres son conocidos por su delincuencia, la prostitución y los problemas sociales, todos los autores suelen ubicar a sus culpables entre la gente adinerada y poderosa de los barrios elegantes. De esta manera se vincula el aspecto arquitectónico con el demográfico de Viena. Pero es más: casas elegantes y hogares acogedores pierden su atractivo al convertirse en escenario de los crímenes más lúgubres. Este papel decisivo de los espacios privados merece sin duda una investigación posterior en una futura ampliación de este artículo. 
Se podría finalizar diciendo que cada autor a su modo dibuja Viena como el espacio que, embellecido con su herencia arquitectónica y con su diseño urbanístico, pretende disimular e incluso ocultar un pasado que sigue presente y cuya energía, a la larga, impregna a muchos de sus habitantes, mientras los visitantes quedan deslumbrados por la Cultura con mayúscula, que las autoridades intentan exportar. El lector queda desorientado ante las complejas combinaciones de estos elementos espaciales y del diverso papel que juegan estos lugares: ¿son los habitantes los responsables o es la toxicidad de las energías, de origen remoto, no asentadas, lo que trastorna sus comportamientos? En cualquier caso, es tentador si se tiene la oportunidad de comprobarlo por uno mismo. Al fin y el cabo, y aunque seguramente habrá alguna honrosa excepción, ¿qué ciudad o qué civilización no se asienta sobre las ruinas de una anterior? ¿Cuántos esqueletos habrá debajo de nuestra propia plaza?

\section{Bibliografía}

BRANDTSTÄTTER, Christian (ed.) (2005): Wien 1900. Kunst und Kultur. Fokus der Europäischen Moderne. München: Deutscher Taschenbuch Verlag.

HAAS, Wolf (1998): Komm, Süßer Tod. Reinbek bei Hamburg: Rohwolt.

HAAS, Wolf (2001): Wie die Tiere. Reinbek bei Hamburg: Rohwolt.

KLEINDEL, Walter (1984): Die Chronik Österreichs. Dortmund: Chronik Verlag.

RAFELSBERGER, Marcus (2009): Menschenteufel. Leck: Emons-Verlag.

ROSSMANN, Eva (2008a): Freudsche Verbrechen. Mira Valensky ermittelt in Wien. Bergisch Gladbach: Bastei Lübbe.

ROSSMANN, Eva (2008b): Ausgejodelt. Mira Valensky ermittelt in Wien. Bergisch Gladbach: Bastei Lübbe.

SCHORSKE, Carl E. (1981): Fin-de-Siècle Vienna: Politics and Culture. New York: Vintage Books.

TALLIS, Frank (2006): Mortal Mischief. London: Arrow Books.

TALLIS, Frank (2009): La Clave del Crimen. Traducción de Raquel Luzárraga. Barcelona, México y Buenos Aires: Grupo Robin Book / As de Diamantes.

WIKIPEDIA (2010): "Gastronomía de Austria" [en línea], en Wikipedia: La enciclopedia libre.

En: http://es.wikipedia.org/wiki/Gastronom\%C3\%ADa de Austria [Consulta: diciembre de 2010]. 